\title{
SPATIAL DISTRIBUTION PATTERN AND ECOLOGICAL NICHE CHARACTERISTICS OF P. SYLUESTRIFORMIS POPULATION IN CHANGBAI MOUNTAIN AREA, CHINA
}

\author{
JiN, H.* - ZHAO, Y. - YIN, H. - HUANG, L. - LIU, L. - CHEN, Q. - DAI, Y. - QIN, L. \\ Jilin Provincial Joint Key Laboratory of Changbai Mountain Biocoenosie an Biodiversity, \\ Changbaishan Academy of Science, CN-133613 Yanbian, P. R. China \\ *Corresponding author \\ e-mail: fivecl10jinhui@163.com
}

(Received 13 ${ }^{\text {th }}$ Jun 2018; accepted $1^{\text {st }}$ Aug 2018)

\begin{abstract}
P. syluestriformis is an endemic plant in Changbai Mountain area of China. Some sample plots were set up in natural distribution communities of $P$. syluestriformis. Based on the survey data of the plots, the spatial distribution pattern of $P$. syluestriformis population was studied by the aggregation index. The niche breadth of Levins, Hurlbert and the Pianka niche overlap methods were used to analyze the niche characteristics of $P$. syluestriformis population in different communities. The results showed that in the pure forest of $P$. syluestriformis at about $700 \mathrm{~m}$ above sea level, $P$. syluestriformis population was in an aggregate distribution state, and in the scattered community of $P$. syluestriformis, $P$. syluestriformis population was randomly distributed in different forest stands under natural conditions, $P$. syluestriformis population had obvious advantages in each resource location. The maximum niche breadth of Levins was 5.3094. In the aspect of niche overlap index, there was a large niche overlap between the population of $P$. syluestriformis and $U$. japonica, which had obvious sharing advantages. Followed by L. olgensis, A. tegmentosum, Q. mongolica, A. nephrolepis. P. syluestriformis population and the above-mentioned associated species had the same or similar requirements for the same resource, and competition would occur when the resources were insufficient. The succession dynamics of $P$. syluestriformis populations were mainly characterized by narrow geographical distribution and narrow habitat, few populations, no individual seedlings and saplings, and lack of self-renewal ability, so they belonged to the recession-type populations.
\end{abstract}

Keywords: $P$. syluestriformis, aggregation degree, niche overlap, niche breadth

\section{Introduction}

The niche is the smallest unit of species distribution. Since Grinnell J proposed niche conception in 1917. The study of niche theory has been one of the research hotspots in the field of world ecology (Grinnell, 1917). Niche theory is widely used in species relations, biodiversity, community structure and function, community succession dynamics, intraspecific and interspecific competition studies.

To analyze the status and relationship of target species in communities, Chinese and foreign scholars used multiple niche breadth and niche overlap formulas to measure the niche characteristics of main populations of different communities. Seen from the existing results, the plant communities that developed on different types of landforms in different regions have different manifestations of their population niche characteristics (Chang et al., 2015; Chen et al., 2010). Among them, Chinese scholars have made relatively successful attempts to study the niche of plant populations in Changbai Mountain, China (Chen et al., 2009; Ye et al., 2011). The research on the population niche characteristics of rare and endangered plants is of great significance for further exploring the utilization of space resources and the interrelationships between other 
endangered plants and other populations, and revealing the mechanism of endangered plants.

P. syluestriformis, is an evergreen tree of Pinus L. and a rare and endangered tree species in Changbai Mountain area of China. The natural population is relatively narrow and is located at $\mathrm{N} 42^{\circ} 06^{\prime}-42^{\circ} 32^{\prime}$, E $128^{\circ} 07^{\prime}-128^{\circ} 21^{\prime}$, scattered on the northern slope of Changbai Mountain, China (Jin et al., 2015).

Due to population increase, economic development and environmental destruction, the distribution area of natural population of $P$. syluestriformis have gradually narrowed and it has reached the edge of extinction. At present, the number of existing plants of $P$. syluestriformis is less than 110000 (Wang, 2007).

Since the 1980s, some Chinese scholars began to pay attention to the special species of $P$. syluestriformis. Aiming at the ecological characteristics, the growth pattern, the introduction and afforestation techniques, the biomass, diversity of interspecific seed traits in population, and so on (Lu et al., 2004; Cheng et al., 2013; Zou et al., 1995), and research cases on the niche characteristics of the rare population of $P$. syluestriformis have not been reported so far. Therefore, in this paper, the field survey data of community of $P$. syluestriformis population distribution as the data source were used to quantitatively measure the niche characteristics of the dominants to reveal the function and status of $P$. syluestriformis population in the community and analyze the interrelation between various groups. It will provide scientific support for judging the stability of $P$. syluestriformis population and theoretical basis for revealing its endangered mechanism.

\section{Material and methods}

\section{Regional survey of research}

The research area is located in the Changbai Mountain Nature Reserve in Jilin, China. The zonal climate belongs to the continental mountain climate with monsoon influence. Winter is cold and dry; summer is warm and humid. The precipitation is mostly concentrated in July-August, with an average annual temperature of $4.4{ }^{\circ} \mathrm{C}$, extreme minimum temperature of $-40{ }^{\circ} \mathrm{C}$, the extreme maximum temperature of $37.5^{\circ} \mathrm{C}$, annual precipitation of $600-1340 \mathrm{~mm}$, relative humidity of more than $70 \%$, and the frost-free period of 90-100 days. The soil in the distribution area of $P$. syluestriformis is mostly formed dark brown soil on volcanic ash. The soil layer is thin, the $\mathrm{pH}$ is 4.2-4.9, the content of humus is low, and the water holding capacity is poor.

The plant in the area belongs to floristic plant of Changbai Mountain. The upper part of the natural distribution area of $P$. syluestriformis is mixed with coniferous forest, and the lower part is interlaced with coniferous and broad-leaved mixed forest belt, forming a unique mixed forest and a small piece of pure forest of $P$. syluestriformis.

\section{Sampling method}

In 2015 , one sample plots of $30 \mathrm{~m} \times 30 \mathrm{~m}$ were set up in the pure forest of $P$. syluestriformis, two sample plots of $30 \mathrm{~m} \times 30 \mathrm{~m}$ were set up in the scattered forest of $P$. syluestriformis in Changbai Mountain Nature Reserve. The species, crown width, coverage and diameter at breast height $(\mathrm{DBH})$ of woody plants with $\mathrm{DBH} \geq 1.3 \mathrm{~cm}$ were investigated and recorded in detail. The sample area was summarized in Table 1. The distribution map of $P$. syluestriformis is shown in Figure 1. 
Table 1. Community habitat and vegetation status in the survey area

\begin{tabular}{|c|c|c|c|c|c|c|c|}
\hline $\begin{array}{l}\text { Sample } \\
\text { number }\end{array}$ & Forest type & Altitude/m & $\begin{array}{c}\text { Falling } \\
\text { gradient }\end{array}$ & Aspect & $\begin{array}{l}\text { Crown } \\
\text { density }\end{array}$ & $\begin{array}{l}\text { Geographic } \\
\text { coordinates }\end{array}$ & $\begin{array}{c}\text { Dominant species of } \\
\text { Arbor layer }\end{array}$ \\
\hline P1 & $\begin{array}{c}\text { The pure forest } \\
\text { of } P \text {. } \\
\text { syluestriformis }\end{array}$ & 700-740 & $<1$ & $\begin{array}{c}\text { Northeast, } \\
\text { near the } \\
\text { plains }\end{array}$ & 70 & $\begin{array}{l}\mathrm{N} 42^{\circ} 25^{\prime} \\
\mathrm{E} 128^{\circ} 07^{\prime}\end{array}$ & $\begin{array}{c}\text { P.syluestriformis, } \\
\text { Q.mongolica, A.mono, } \\
\text { U.japonica, } \\
\text { A.pseudosieboldianum, } \\
\text { F.mandshurica, } \\
\text { T.mandschurica }\end{array}$ \\
\hline $\mathrm{P} 2$ & $\begin{array}{l}\text { The scattered } \\
\text { forest of } P \text {. } \\
\text { syluestriformis }\end{array}$ & 890-984 & 3 & Southeast & 75 & $\begin{array}{l}\mathrm{N} 42^{\circ} 18^{\prime} \\
\mathrm{E} 128^{\circ} 06^{\prime}\end{array}$ & $\begin{array}{c}\text { P.syluestriformis, } \\
\text { Q.mongolica, } \\
\text { A.nephrolepis, } \\
\text { L.olgensis, } \\
\text { A.mono, T.amurensis, } \\
\text { P.koraiensis, A. kalkora, } \\
\text { P jezoensis }\end{array}$ \\
\hline P3 & $\begin{array}{l}\text { The scattered } \\
\text { forest of } P \text {. } \\
\text { syluestriformis }\end{array}$ & $1100-1180$ & $<3$ & North & 80 & $\begin{array}{l}\mathrm{N} 42^{\circ} 10^{\prime} \\
\mathrm{E} 128^{\circ} 08^{\prime}\end{array}$ & $\begin{array}{c}\text { P.syluestriformis, } \\
\text { T.amurensis, } \\
\text { A.nephrolepis, } \\
\text { L.olgensis, } \\
\text { A. mono, B.platyphylla, } \\
\text { P.davidiana, } \\
\text { T.amurensis, } \\
\text { P.jezoensis, } \\
\text { A.tegmentosum }\end{array}$ \\
\hline
\end{tabular}
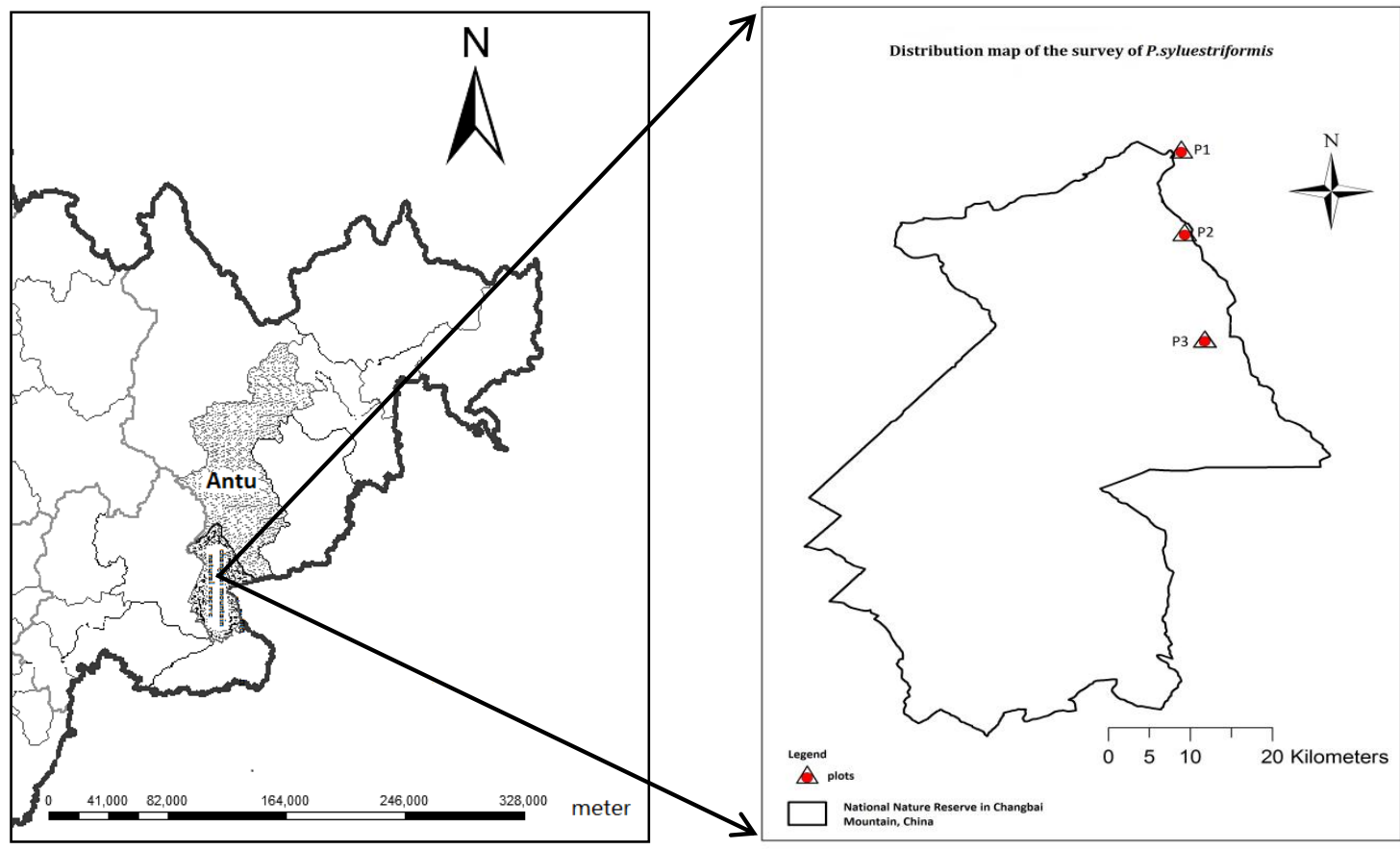

Figure 1. Distribution map of the survey of $P$. syluestriformis 


\section{Data processing}

\section{Population distribution pattern measurement method}

There are many mathematical models for determining the types of distribution patterns of biological populations. In practical applications, each model has its adaptive application effect and the method is simple and effective. This paper combines with five kinds of aggregation index, such as the diffusion coefficient $(C)$, aggregation index $(I)$, average congestion $\left(M^{*}\right)$, convergence index $\left(M^{*} / x\right)$ and $M$ index $\left(C_{A}\right)$. The distribution pattern is determined by means of $t$ test of mean variance and $F$ test of deviation degree of random distribution, and the population aggregation is determined by negative binomial parameters (K) (Wang, 2012; Guo, 2004).

Niche breadth (Hurlbert, 1978; Li et al., 2003)

$$
B i=\frac{1}{r \sum_{j=1}^{r} P_{i j}^{2}}
$$

Equation 1 of Levins (1968) is quantitatively calculated, $\gamma$ is the number of resource bits, $P_{i j}$ is the proportion of the species is using the $j$-th resource for all resources and is the population number; the niche breadth range is $[1 / \gamma, 1]$.

$$
B_{a}=\frac{1}{\sum_{j=1}^{n} \frac{p_{j}^{2}}{a_{j}}}
$$

Equation 2 stands for Hurlbert niche breadth index. $P_{j}$ is the proportion of the species $i$ that uses the $j$-th resource to the total resource bit used by the species, $a_{j}$ is the number of items available in resources $j\left(\Sigma a_{j}=1.0\right), B_{a}$ is the standardized Hurlbert niche breadth index.

Niche overlap (Hurlbert, 1978)

$$
O_{i k}=\sum_{j=1}^{r} P_{i j} P_{k j} / \sqrt{\left(\sum_{j=1}^{r} P_{i j}\right)^{2}\left(\sum_{j=1}^{r} P_{k j}\right)^{2}}
$$

Pianka (1973) overlap index was used for analysis. In Equation 3, $O_{i k}$ value is between 0 and 1 .

\section{Age class division of $P$. syluestriformis}

For the classification of age class of $P$. syluestriformis, this paper takes 30 years as an age class, altogether divides into 8 age classes, which are I grade, II grade, III grade, IV grade, V grade, VI grade, VII grade, VIII grade. Those over 240 years old are classified as VIII grade. 


\section{Data statistical analysis}

The original data is input into Excel table, and the data format can be read by $\mathrm{R}$ software according to the need of analysis. The spatial distribution pattern is analyzed, using the Riplely correlation function in the Spatstat library of R software.

\section{Results}

\section{Spatial distribution pattern of P. syluestriformis population}

According to the survey sample data, the indexes mentioned above of aggregation were measured by distribution (Table 2). It could be seen from the results in the table that the maximum diffusion coefficient of P2 sample plot was 2.243, which was greater than 1, and the diffusion coefficient of other sample plots was less than 1. After comparing $t$ and $t 0.05(36-1)$, both reached significant level of difference. According to the analysis of sample plots, the pure forest community of $P$. syluestriformis presented a clustered distribution. While in the scattered forests, the distribution state showed random and scattered in various forest communities. The $M * / x$ index was greater than 1 in P2 sample plots, the indexes in the other samples were all less than 1. To more accurately reflect the spatial pattern of a natural population of $P$. syluestriformis in different habitats, the regression analysis of 6 plots $M * / x$ of scattered forests was carried out. The regression equation was as follows: $M^{*}=-0.05161+0.43806 x R=0.6927$. In the regression relationship, the $\alpha$ value was -0.05161 , which was approximately 0 , indicating that the basic component of the distribution was a single individual. The space $\beta$ used to explain the basic component, the $\beta$ value was 0.43806 , and the value $\beta$ was $<1$, which was a uniform distribution. Using the statistical method of Taylor's power law, the regression equation was: $\lg S^{2}=-0.16858+0.88407 \lg x R=0.9959$, further confirmed that the populations of $P$. syluestriformis were scattered in the communities in the scattered state.

Table 2. Spatial distribution and aggregation index of $P$. syluestriformis population

\begin{tabular}{c|c|c|c|c|c|c|c|c}
\hline $\begin{array}{c}\text { Sample } \\
\text { number }\end{array}$ & $\bar{x}$ & $\boldsymbol{S}^{2}$ & $\begin{array}{c}\text { Diffusion } \\
\text { coefficient } \boldsymbol{C}\end{array}$ & $\boldsymbol{I}$ index & $\begin{array}{c}\text { Average } \\
\text { congestion } \boldsymbol{M}^{*}\end{array}$ & $\boldsymbol{M} * \boldsymbol{x}$ index & $\begin{array}{c}\boldsymbol{C}_{\boldsymbol{A}} \\
\text { index }\end{array}$ & $\begin{array}{c}\text { Distribution } \\
\text { pattern }\end{array}$ \\
\hline P1 & 1.750 & 2.243 & $2.4933^{* *}$ & 1.4933 & 2.0317 & 1.1610 & 0.1610 & $C$ \\
P2 & 0.278 & 0.201 & $0.7221^{* *}$ & -0.2779 & -0.0001 & -0.0004 & -1.0004 & $R$ \\
P3 & 0.056 & 0.052 & $0.9437^{* *}$ & -0.0563 & -0.0007 & -0.0128 & -1.0128 & $R$ \\
\hline
\end{tabular}

$C$ : cluster distribution, $R$ : random

The spatial distribution pattern of a natural population of $P$. syluestriformis was analyzed by using $C, M^{*}, C_{A}$ index. The results showed in Table 3 that in pure forest there was no individual of $P$. syluestriformis in addition to VIII age-class, and there were distributions at all other levels, of which III and IV age-classes were clustered, and other age-classes were random. It also showed that the population had a certain diffusivity from young to mature individuals, and $C, C_{A}$ had the same result of judgment. In pure forest community, the spatial distribution pattern of $P$. syluestriformis population changed from young to mature, which was a general trend from random type to clustered type and then to random type. 
Table 3. Aggregation degree of distribution pattern of different age classes of $P$. syluestriformis population

\begin{tabular}{c|c|c|c|c|c|c}
\hline $\begin{array}{c}\text { Sample } \\
\text { number }\end{array}$ & $\begin{array}{c}\text { Age- } \\
\text { class }\end{array}$ & $\begin{array}{c}\text { Diffusion } \\
\text { coefficient } \boldsymbol{C}\end{array}$ & $\begin{array}{c}\text { Average } \\
\text { congestion } \boldsymbol{M}^{*}\end{array}$ & $\boldsymbol{M}^{*} / \boldsymbol{x}$ index & $\boldsymbol{C}_{A}$ index & $\begin{array}{c}\text { Distribution } \\
\text { pattern }\end{array}$ \\
\hline \multirow{6}{*}{ P1 } & I & 0.9306 & 0.0000 & 0.0001 & -0.9999 & $R$ \\
& II & 0.8472 & 0.2222 & 0.5926 & -0.4074 & $R$ \\
& III & 1.0708 & 0.9180 & 1.0836 & 0.0836 & $C$ \\
& IV & 1.0853 & 0.5714 & 1.1755 & 0.1755 & $C$ \\
& V & 0.9722 & -0.0000 & -0.0005 & -1.0005 & $R$ \\
& VI & 0.9583 & 0.0000 & 0.0001 & -0.9999 & $R$ \\
& VII & 0.9722 & -0.0000 & -0.0005 & -1.0005 & $R$ \\
& VIII & - & - & - & - & $N$ \\
\hline \multirow{4}{*}{ P2 } & I & 1.0000 & 0.0069 & 1.0000 & 0.0000 & $R$ \\
& II III & - & - & - & - & $N$ \\
& IV & 0.9930 & 0.0069 & 0.4972 & -0.5028 & $R$ \\
& V & 0.9650 & 0.0067 & 0.1608 & -0.8392 & $R$ \\
& VI & 0.9720 & 0.0068 & 0.1946 & -0.8054 & $R$ \\
& VII & 0.9720 & 0.0068 & 0.1946 & -0.8054 & $R$ \\
& VIII & 0.9510 & 0.0066 & 0.1187 & -0.8813 & $R$ \\
\hline \multirow{4}{*}{ P3 } & I V & - & - & - & - & $N$ \\
& VI & 0.9444 & -0.0000 & -0.0002 & -1.0002 & $R$ \\
& VII & 0.9167 & 0.0000 & 0.0001 & -0.9999 & $R$ \\
& VIII & 0.9861 & -0.0000 & -0.0005 & -1.0005 & $R$ \\
\hline
\end{tabular}

$C$ : cluster distribution, $R$ : random, $N$ : lack of this type

However, aggregation index of $P$. syluestriformis population of the scattered community below $1000 \mathrm{~m}$ above sea level showed that only one individual of I ageclass was present in the investigated community, the individuals of II-III age-classes were missing, and the individuals of IV-VIII age-classes were randomly distributed.

Aggregation index of $P$. syluestriformis population of the scattered community above $1000 \mathrm{~m}$ above sea level showed that there were no individuals of I-V age-classes in the community, and only individuals of VI-VIII age-classes had the spatial distribution pattern of random distribution.

\section{Analysis of niche breadth measurement results}

Niche breadth is an indirect measurement of the scale and population dynamics of the population's ability to use environmental resources. The niche breadth depends on the quantitative expression of species' position and role in the community, which can better explain the environmental adaptability and resource utilization ability of the population during the succession process. The greater the niche breadth of the population, the stronger its ability to adapt to the environment, the fuller the utilization of various resources, and the more dominant position it often plays in the community. To overcome the impossibility of comparing the niche of different communities and within the same community, levins index and Hurlbert index were used to study the niche breadths of major populations. Comprehensive analysis of survey plots, niche 
breadths were calculated of 12 species with relatively high important value and wide distribution range by using Equations 1 and 2.

It could be seen in Table 4 that the order of the levins niche breadth index was P. syluestriformis $>$ A. nephrolepis $>$ L. olgensis $>$ B. platyphylla $>$ T. amurensis $>U$. japonica $>$ A. tegmentosum $>$ Q. mongolica $>\mathrm{P}$. jezoensis $>$ A. mono $>\mathrm{S}$. pohuashanensis $>\mathrm{P}$. koraiensis. The maximum of Levins niche breadth of $\mathrm{P}$. syluestriformis population was 5.3094, indicating that P. syluestriformis had obvious superiority in each resource location. As one of the community species, it was distributed in 8 resource locations. The second was A. nephrolepis, and the Levins niche breadth was 4.1782, and it also occupied a wide range of niches. It was distributed in all six resource locations except for pure forests. B. platyphylla and T. amurensis had wide niche amplitude and wide distribution, the Levins niche breadth was 3.3196 and 3.1864, respectively. L. olgensis and P. koraiensis were the main associated tree species in the arbor layer of scattered communities, and the Levins niche breadth was 3.4050 and 2.3611, respectively.

Table 4. Niche breadth of main species in arbor layer of $P$. syluestriformis community

\begin{tabular}{c|c|c|c|c|c|c|c|c|c|c}
\hline Species number & $\boldsymbol{P i 1}$ & $\boldsymbol{P i 2}$ & $\boldsymbol{P i 3}$ & $\boldsymbol{P i 4}$ & $\boldsymbol{P i 5}$ & $\boldsymbol{P i 6}$ & $\boldsymbol{P i 7}$ & $\boldsymbol{P i 8}$ & $\boldsymbol{B i}$ & $\boldsymbol{B a}$ \\
\hline P. syluestriformis & 0.265 & 0.273 & 0.083 & 0.083 & 0.040 & 0.130 & 0.021 & 0.106 & 5.3094 & 0.6637 \\
Q. mongolica & 0.034 & 0.009 & 0.134 & 0.505 & 0.000 & 0.000 & 0.000 & 0.318 & 2.6626 & 0.5325 \\
T. amurensis & 0.048 & 0.018 & 0.000 & 0.462 & 0.242 & 0.000 & 0.197 & 0.034 & 3.1864 & 0.5311 \\
U. japonica & 0.314 & 0.228 & 0.456 & 0.000 & 0.000 & 0.000 & 0.000 & 0.000 & 2.7771 & 0.9257 \\
P. jezoensis & 0.000 & 0.016 & 0.000 & 0.299 & 0.000 & 0.011 & 0.534 & 0.139 & 2.5296 & 0.5059 \\
L. olgensis & 0.000 & 0.000 & 0.339 & 0.290 & 0.000 & 0.299 & 0.072 & 0.000 & 3.4050 & 0.8513 \\
B. platyphylla & 0.049 & 0.004 & 0.383 & 0.054 & 0.000 & 0.035 & 0.370 & 0.104 & 3.3196 & 0.4742 \\
A. mono & 0.001 & 0.000 & 0.208 & 0.000 & 0.000 & 0.103 & 0.580 & 0.108 & 2.4885 & 0.4977 \\
P. koraiensis & 0.000 & 0.000 & 0.011 & 0.034 & 0.572 & 0.021 & 0.302 & 0.059 & 2.3611 & 0.3935 \\
A. nephrolepis & 0.000 & 0.000 & 0.001 & 0.355 & 0.090 & 0.141 & 0.205 & 0.209 & 4.1782 & 0.6964 \\
S. pohuashanensis & 0.000 & 0.000 & 0.026 & 0.061 & 0.000 & 0.061 & 0.270 & 0.583 & 2.3638 & 0.4728 \\
A. tegmentosum & 0.029 & 0.000 & 0.107 & 0.126 & 0.000 & 0.555 & 0.184 & 0.000 & 2.7089 & 0.5418 \\
\hline
\end{tabular}

Taking full account of the fact that the resource status was highly variable under actual circumstances, the Hurlbert niche breadth value was calculated. The index took into account the magnitude of each resource's state. The analysis data showed that the Hurlbert niche breadth was the largest due to $U$. japonica, it had a larger important value in the $P$. syluestriformis pure forest, its utilization of resources and space in forest was similar to that of $P$. syluestriformis. The Hurlbert niche breadth of other species were basically the same as the Levins niche breadth, which reflected the status and the distribution range of major arbor populations determined the niche breadth.

\section{Analysis of niche overlap measurement results}

Niche overlap is the similarity between two species in relation to ecological factors. Niche overlap occurs when two species use the same resource or share one resource (food, nutrients, space, etc.). Niche overlaps make connections between species, and the niche overlap value can explain the competition or coexistence between species. 
Calculation of niche overlap index by Equation 3, as shown in Table 5, the maximum niche overlap occurred between A. mono and B. platyphyll, followed by $A$. Nephrolepis and T. amurensis, indicating that there may be higher niche overlap among species with narrow niche breadth. There was a large niche overlap between $P$. syluestriformis and $U$. japonica population, with an overlap index of 0.704 , followed by L. olgensis, A. tegmentosum, Q. mongolica, L. olgensis and A. nephrolepis, with niche overlap indices of $0.395,0.392,0.369,0.368$ and 0.367 , respectively.

In the communities of natural $P$. syluestriformis population, the degree of niche overlap of various populations was great, the relationship between species was complex, the trend of resource sharing was obvious, and the utilization of resources by species was similar. The niche overlap of populations with large importance value and wide niche breadth was greater than that of other populations. On the contrary, the niche overlap of populations with small importance value and narrow niche breadth was smaller than that of other populations.

Table 5. Niche overlaps of main species in arbor layer of P. syluestriformis community

\begin{tabular}{|c|c|c|c|c|c|c|c|c|c|c|c|c|}
\hline Species & 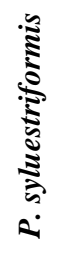 & 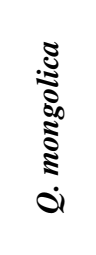 & 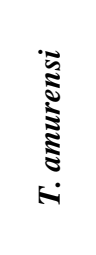 & 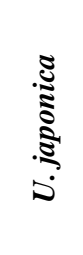 & 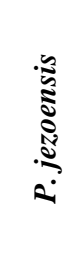 & 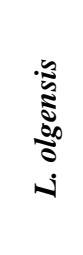 & 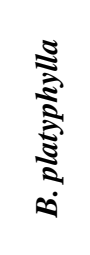 & $\begin{array}{l}\stackrel{8}{5} \\
\stackrel{5}{\Xi} \\
\dot{\nabla}\end{array}$ & 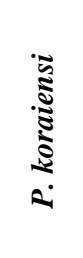 & 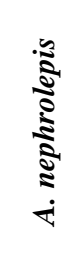 & 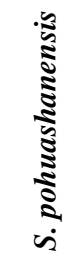 & 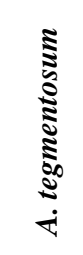 \\
\hline P. syluestriformis & 1 & 0.368 & 0.302 & 0.704 & 0.206 & 0.395 & 0.310 & 0.198 & 0.148 & 0.367 & 0.291 & 0.392 \\
\hline Q. mongolica & & 1 & 0.716 & 0.201 & 0.507 & 0.578 & 0.337 & 0.161 & 0.094 & 0.820 & 0.550 & 0.212 \\
\hline T. amurensis & & & 1 & 0.058 & 0.703 & 0.488 & 0.337 & 0.331 & 0.590 & 0.849 & 0.276 & 0.280 \\
\hline U. japonica & & & & 1 & 0.007 & 0.477 & 0.583 & 0.251 & 0.013 & 0.002 & 0.029 & 0.160 \\
\hline P. jezoensis & & & & & 1 & 0.377 & 0.664 & 0.820 & 0.440 & 0.801 & 0.602 & 0.371 \\
\hline L. olgensis & & & & & & 1 & 0.614 & 0.416 & 0.118 & 0.604 & 0.178 & 0.765 \\
\hline B. platyphylla & & & & & & & 1 & 0.888 & 0.349 & 0.454 & 0.493 & 0.409 \\
\hline A. mono & & & & & & & & 1 & 0.450 & 0.504 & 0.563 & 0.482 \\
\hline P. koraiensis & & & & & & & & & 1 & 0.442 & 0.284 & 0.183 \\
\hline A. nephrolepis & & & & & & & & & & 1 & 0.651 & 0.539 \\
\hline S. pohuashanensis & & & & & & & & & & & 1 & 0.235 \\
\hline A. tegmentosum & & & & & & & & & & & & 1 \\
\hline
\end{tabular}

\section{Discussion}

The niche breadth of the populations in each community depends on the adaptability of the species to the environment, the intensity of interspecific competition, and the distribution of environmental factors (Chen et al., 2014).

This research found that the niche breadth of $P$. syluestriformis was large in the community, indicating that the species had strong adaptability to the environment. Wei Zhiqin and others thought that rare and endangered plants were mostly inhibited in the community, and the niche was very narrow (Wei et al., 2004). The conclusion of this study is contrary to it. The reason may be that, on the one hand, it is possible that the purpose of the study is to use $P$. syluestriformis as the target tree. When selecting the 
plots, the gathering community of $P$. syluestriformis was artificially selected as the survey site, but this did not affect the community structure and its status in the community. On the one hand, it may be because P. syluestriformis itself had a special habitat requirement, and the population had a widening niche breadth to obtain sufficient resources (Zhang, 2011).

This research reflects that the view is consistent with Liu Wei's research on the niche of main plant species of the Spruce-fir forests in Changbai Mountain, that is, the greater niche breadth, the greater overlap (Liu and Cao, 2011). However, due to the individual niche breadth, the species' biological and ecological characteristics are unnecessarily the same, and the niche overlap between them is unnecessarily high. It is considered that the decrease in the degree of overlap reflects the differentiation of inter-species resource utilization ( $\mathrm{Du}$ et al., 2015). Therefore, for species pairs with large niche overlap in the community, it is considered that there are two possibilities: one is that there is a competitive relationship while sharing resources among the species, and the other is that the resources are similarly used while promoting the relationship between the species (Xu et al., 2014). Vannette proposed the niche construction hypothesis, which held the view that if the niche of species was divided into three parts: niche overlap between species, the environmental impact niche and the requirement niche of environmental resources, the prediction of community construction based on niche would be more accurate (Vannette and Fukami, 2014).

Field investigations showed that there were fewer young seedlings of $P$. syluestriformis under the forest, indicating that the habitat of $P$. syluestriformis was higher than the interaction between the species. This paper only explored the resource utilization status between $P$. syluestriformis and the current community dominant species from the perspective of community science. The resource utilization ability of $P$. syluestriformis under different growth conditions was not compared, and further research would be needed. Besides, the distribution of two communities of $P$. syluestriformis could be regarded as the key protection habitat, and the difference of population dynamics caused by the difference of their habitats needed to be further explored.

\section{Conclusions}

The research showed that populations with similar habitat requirements could form a good symbiotic relationship under the condition of sufficient resources, which supported the theory that niche overlap and competition were not related. There were relatively few individuals in each resource location of $P$. syluestriformis, and most of them were older, occupying the absolute superiority in the height niche of the arbor layer, and occupying the upper layer of the forest canopy and occupying the absolute dominant position in the community.Therefore, this advantage of $P$. syluestriformis was temporary, and the succession dynamics of $P$. syluestriformis populations were mainly characterized by narrow geographical distribution and narrow habitat, few populations, no individual seedlings and saplings, and lack of self-renewal ability, so they belonged to the recession-type populations. After a certain period of succession, it would probably be replaced by other arbor species, which had many saplings, and had relatively large niche overlap with its $P$. syluestriformis, such as $P$. koraiensis, $A$. nephrolepis, and so on. 
The reason for the rarity of $P$. syluestriformis was mainly caused by the combination of internal and external factors. The internal factors were the defects of ecological and biological characteristics of $P$. syluestriformis. The ecological adaptability of $P$. syluestriformis was relatively narrow and the distribution area was limited; the seed regeneration was difficult, and the ability of self-regeneration was extremely lacking; the resources for the growth of seedlings and saplings were limited. External factors included historical overuse and habitat destruction, and natural communities were largely absent. Therefore, the community resources of Changbai Mountain area were very rare. The protection of wild populations and their habitats of $P$. syluestriformis was the most effective protection measure. With establishment of a different forest for further implementation of $P$. syluestriformis by local conservation and artificial cultivation, the artificial cultivated individuals were transplanted into their original habitats. In this way, they could be naturalized into the natural environment, could develop normally and produce future generations, and consequently expand the size of natural populations.

Acknowledgements. This research was financially supported by the 12th Five-Year Plan National Science and Technology support Project of China (Grant No. 2012BAD22B040102), and the Scientific and Technological Development Project of Jilin Province, China (Grant No. 20180101017JC).

\section{REFERENCES}

[1] Chang, C., Wang, X., Yang, R. et al. (2015): A quantitative characterization method for alpine vegetation zone based on DEM and NDVI. - Geographical Research 34(11): 21132123.

[2] Chen, J., Liu, X. L., He, F. et al. (2010): Niche characteristics of dominant woody populations in Quercus Aquifo Liodes shrub community in Balangshan Mountain in Wolong Nature Reserve. - Scientia Silvae Sinicae 46(3): 23-28.

[3] Chen, X., Bu, Z. J., Wang, S. Z. et al. (2009): Niches of seven bryophyte species in Hani peat land of Changbai Mountains. - Yingyong Shengtai Xuebao 20(3): 574-578.

[4] Chen, Y. K., Yang, Q., Mo, Y. N. et al. (2014): A study on the niches of the states key protected plants in Bawangling, Hainan Island. - Chinese Journal of Plant Ecology 38(6): 576-584.

[5] Cheng, J. Y., Cao, W. J., Yang, L. (2013): Research on wild interindividual seed trait diversity of $P$. syluestriformis. - Journal of Jilin Forestry Science and Technology 42(1): $1-5$.

[6] Du, D. L., Su, J., Liu, Y. C. et al. (2015): Study on the niche of Gordonia acuminata population in Jinyun mountain. - Guihaia 19(4): 315-322.

[7] Grinnell, J. (1917): The niche-relations of the California Thrasher. - Auk 34: 427-433.

[8] Guo, H. (2004): Studies on Spatial Pattern of Larix chinensis Populations in Qinling Mountain. - Shanxi Normal University, Xi'an, China.

[9] Hurlbert, S. H. (1978): The measurement of niche overlap and some relatives. - Ecology 59: 67-77.

[10] Jin, H., Zhao, Y., Zhao, W. et al.(2015): Natural population status and endangered mechanism of Pinus sylvestriformis in Changbai Mountain. - Journal of Beihua University (Natural Science) 16(5): 661-665.

[11] Levins, R. (1968): Evolution in Changing Environments: Some Theoretical Explorations. - Princeton University Press, USA.

[12] Li, J., Zhu, J. Z., Zhu, Q. K.(2003): A review on niche theory and niche metrics. - Journal of Beijing Forestry University 25(1): 100-107. 
[13] Liu, W., Cao, W. (2011): Niche characteristics of main plant species in spruce-fir forests in Changbai Mountains. - Chinese Journal of Ecology 30(8): 1766-1774.

[14] Lu, Z., Ni, B. C., Fan, R. H. et al. (2004): Introduction research on P. sylvestriformis. Forestry Survey and Design 141(1): 32-34.

[15] Pianka, E. R. (1973): The structure of lizard communities. - Annual Review of Ecology and Systematics 4: 53-74.

[16] Vannette, R. L., Fukami, T. (2014): Historical contingency in species interactions: towards niche-based predictions. - Ecology Letters 17(1): 115-124.

[17] Wang, S. X. (2007): Biological Resources of Changbai Mountain Protection and Development Zone. - Liaoning Science and Technology Press, Shenyang, China.

[18] Wang, W. (2012): Characteristics of Reproduction and Spread for Aconitum leucostomum Worosch Population in Nalati Mountain Meadow. - Xinjiang Agricultural University, Urumchi, China.

[19] Wei, Z. Q., Li, X. G., He, Y. Q. et al. (2004): Study of niche characteristics of the main tree populations of a rare and endangered plant community. - Journal of Southwest Agricultural University (Natural Science) 26(1): 1-4.

[20] Xu, D. J., Wang, P. P., He, Y. J. et al. (2014): Niche characteristics of dominant plant populations of Alsophila spinulosa community of Danxia landform in North Guizhou. Bulletin of Botanical Research 34(5): 612-618.

[21] Ye, J., Hao, Z. Q., Xie, P. et al. (2011): Habitat associations of saplings and adults in an old-growth temperate forest in the Changbai Mountains, northeastern China. - Forestry Studies in China 13(1): 13-22.

[22] Zhang, J. T. (2011): Mathematical Biology. - Science Press, Beijing, China.

[23] Zou, C. J., Bu, J., Xu, W. D. (1995): Biomass and productivity of P. sylvestriformis plantation. - Chinese Journal of Applied Ecology 6(2): 123-127. 